\title{
UNEXPLAINED DEATH OF A BLACK BEAR
}

RANDOLPH J. SEGUIN, Saskatchewan Environment and Resource Management, Box 580, Meadow Lake, Saskatchewan. SOM 1 VO

In 1973, Poelker and Hartwell stated, "Information on natural mortality of black bear is limited." This is as true today as it was at that time. In 1993, as part of a Black Bear study in the southern boreal forest of west-central Saskatchewan, north of Meadow Lake, winter den searches were conducted. During one search the rare event of encountering the carcass of a Black Bear, apparently dead of "natural" causes, occurred.

Case History On 1 June 1992, a black adult female bear was trapped some 30 miles north of Meadow Lake. She measured 59 in. in length and $30 \mathrm{in}$. in girth. The width of the forepaw was 3.5 in. She weighed 130 pounds. Later analysis of the cementum annuli of an extracted tooth indicated that she was 5.25 years old. ${ }^{6}$ She was lactating and a single cub-of-the-year was in attendance.

She was tranquillized, collared with a radio transmitter, allowed to recover and left the trap site with the cub at heel. Through the summer, activity patterns were monitored and her geographic location was determined nine times based on satellite telemetry. She went to den between 15 and 18 October 1992.

Aerial surveys to establish preliminary den locations were conducted 3 to 5 March 1993, inclusive. Locations were recorded through the use of a Global Positioning System. Ground site inspections were conducted on

\section{5 and 26 March 1993.}

During the ground site inspection on 25 March 1993, she was located approximately 500-600 yards from her estimated den location. She was dead, but without a readily apparent cause (i.e., no visible wounds). The inspection team returned to the site on 1 April to retrieve the carcass.

Cause of Death Investigations The carcass was submitted to Drs. G. Wobeser, $\mathrm{H}$. Philibert, and Ted Leighton of the Department of Veterinary Medicine, Western College of Veterinary Medicine, University of Saskatchewan, Saskatoon (Path\#: N93-1687).

At a gross level of examination the animal was deemed to be in good condition and weighed about 108 pounds at the time of death (about 3 to 4 pounds lighter than the actual weight of the carcass due to loss of bodily fluids and some scavenging which had taken place). A mass of "tightly packed and interwoven hair and grass fibres" was located in the intestine. No other unusual findings were noted (G. Wobeser, pers. comm.).

The histopathology conducted on the urinary bladder, intestines, skin, brain, kidney, spleen, stomach, lymph nodes, pancreas, lung, heart, adrenal gland and liver revealed no significant abnormalities. Likewise, efforts at bacteriological cultures 


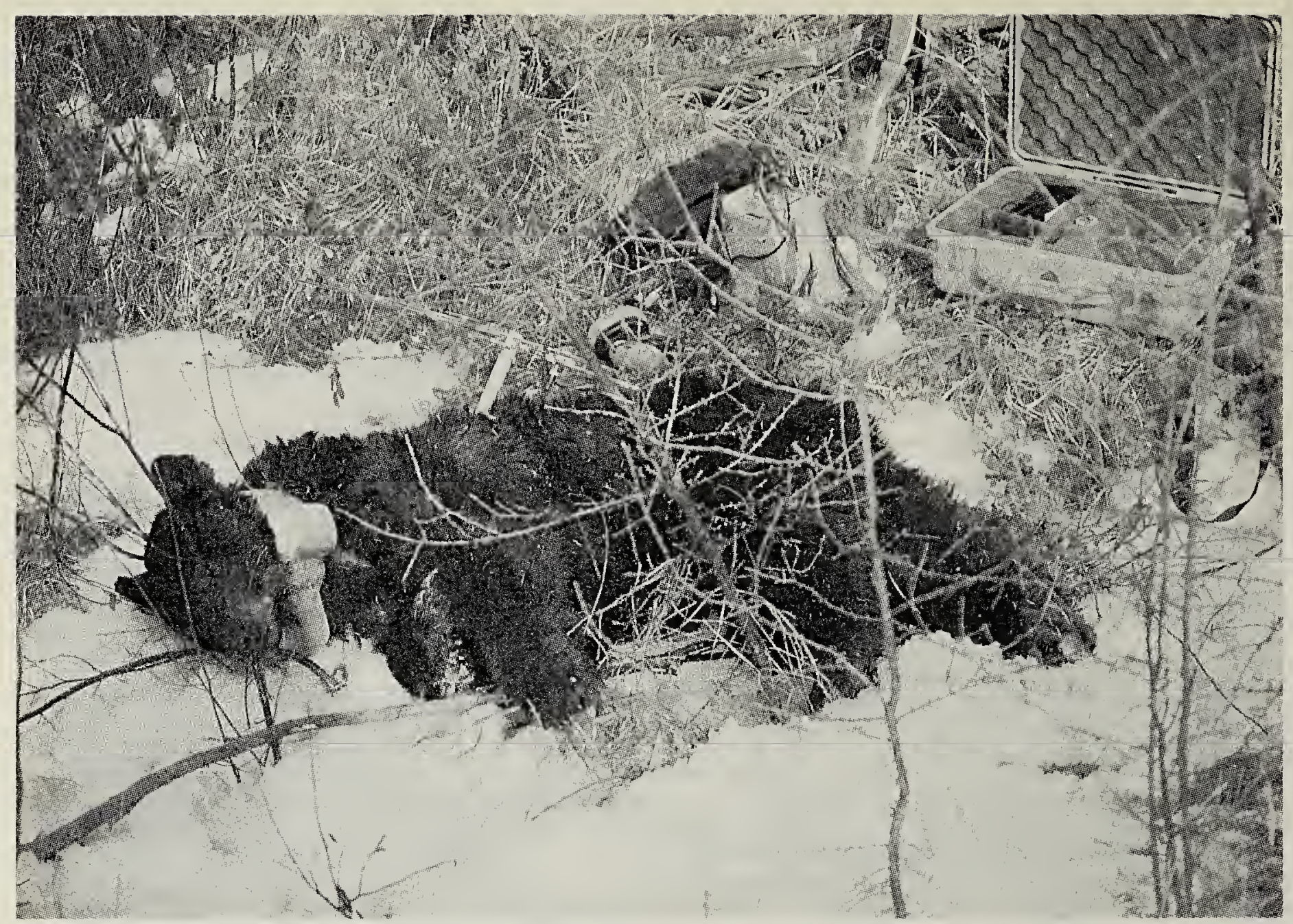

Female Black Bear found dead of "natural" causes,

Meadow Lake Provincial Park.

Randy Seguin

from the lung, kidney, liver, spleen and meningie were inconclusive. The pathologic diagnosis referenced "no significant findings". Comments accompanying the pathologist report stated, "The cause of death was not determined." Dr. Wobeser indicated that whatever the cause of death might have been, it was not related to the effects of being tranquillized or radio collared (pers. comm.).

Discussion Two items in the pathology report should be further examined. First, the animal being in "good condition" refers primarily to the amount of body fat present on the carcass. In the previous year, after several months of spring feeding, she weighed only about 20 pounds more than at the time of death. This is readily explainable based on her having just come through the winter denning period (weight losses of 2030 percent being common) and hav- ing had no opportunity to feed during the spring prior to her death.

Second, the occurrence of the "tightly woven mass" in the intestine is not surprising. I suspect it was what is commonly referred to as a fecal plug. These masses apparently occur in all hibernating Black Bears and are dispelled in the spring soon after den exit. These fecal plugs are often found near den sites.

Summary The rarity of finding a Black Bear dead at the den site is illustrated by a paucity of reports in the literature. Two reports by each of Cardoza and Jonkel refer to a singular citation of Wright in 1910 who claimed to have found bears dead in their dens. ${ }^{1,3}$ Jonkel then immediately states, "Despite these claims, mortality during the denning period must be low." 3 In reviewing 22 articles from various sources that 


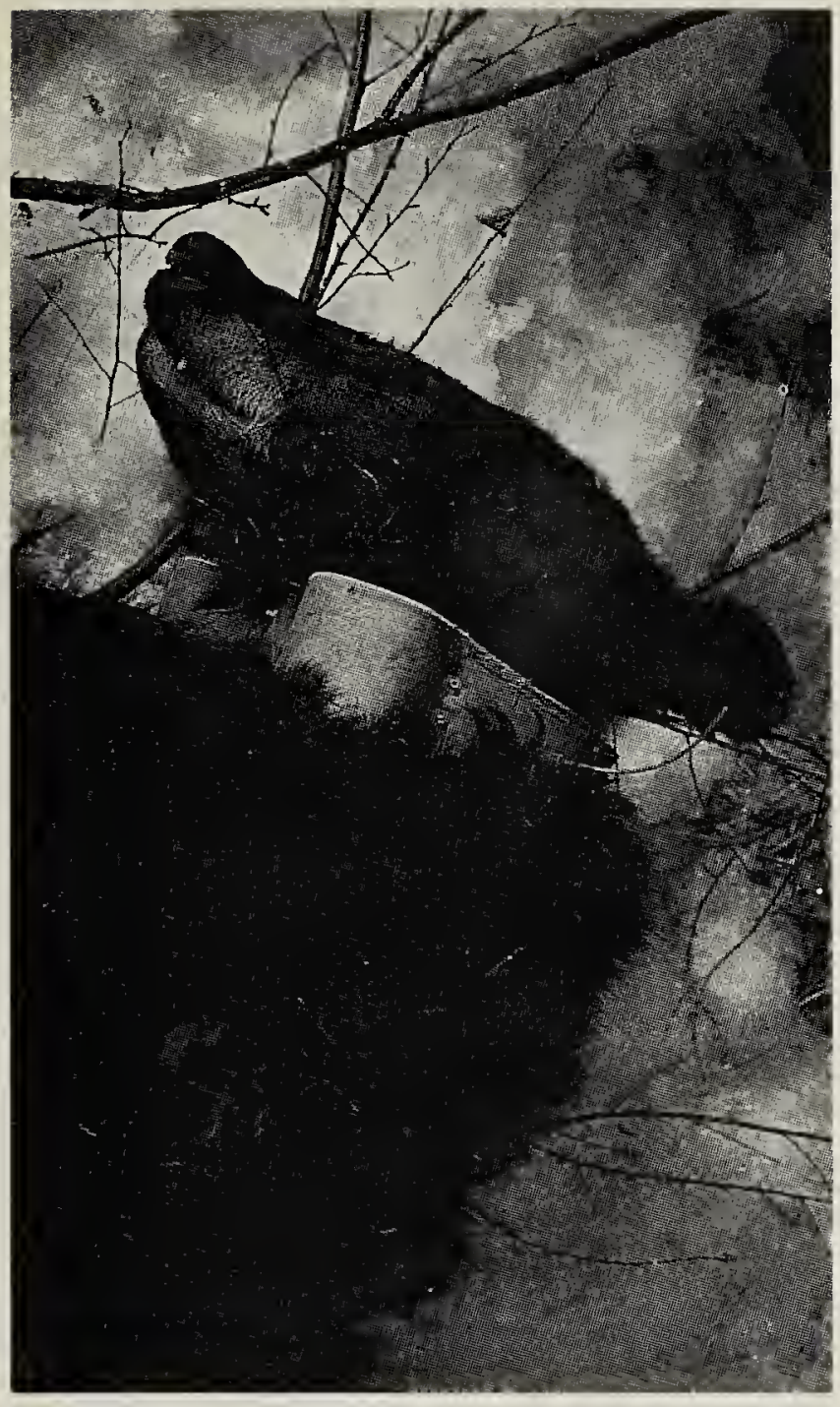

Dead female Black Bear.

Randy Seguin

involved work at den sites, I encountered no death notations.

Information with respect to disease in Black Bears is primarily based on examination of hunter-killed animals or blood serum investigations. A 1991, State of California report sums up the disease situation in Black Bears as follows: "while bear may be exposed to disease, it is a minor factor in overall bear mortality." 5 Garfield in his review paper stated "hibernating hosts display increased resistance to microbial infection." Thus, it is perhaps not surprising that no disease was identified as the cause of death of this denning bear, but it does beg the question, "What was the cause of death?"

Acknowledgements This work was carried out as part of a Black Bear study sanctioned under the Partnership Agreement in Forestry program. I would like to thank Ed Beveridge and Ian McMurchy, Saskatchewan Environment and Resource Management, for their diligence in locating den sites. Added thanks go to Ed and Harvey Penner for their extraordinary efforts in retrieving the carcass. I would also like to thank the Canadian Cooperative Wildlife Health Centre for funding the necropsy and pathology investigations.

1. CARDOZA, J.E. 1976. The history and status of the Black Bear in Massachusetts and adjacent New England States. Massachusetts Division of Fisheries and Wildlife, Westborough, Massachusetts. Research Bulletin $18.113 \mathrm{pp}$.

2. GARFIELD, E. 1988. Nothing to snooze at: exploring the mysteries of hibernation. Current Contents 20:3-9.

3. JONKEL, C.J. 1967. Black Bear population studies. Big Game Research, Bozeman, Montana. State of Montana Job Completion Report. No. W-98-R-1. 148 pp.

4. POELKER, R.J. and H.D. HARTWELL. 1973. Black Bear of Washington. Washington State Game Department, Olympia, Washington. Biological Bulletin No. 14. 180 pp.

5. RESOURCES AGENCY, CALIFORNIA DEPARTMENT OF FISH AND GAME. 1991. Draft environmental document regarding: bear hunting. Sacramento, California. 233 pp. + appendices.

6. WILLEY, C.H. 1974. Aging Black Bears from first premolar tooth sections. J. Wildl. Manage. 38:97-100. 